\title{
Acute decompensated heart failure
}

\author{
Serge Lepage MD
}

\section{$\mathrm{S}$ Lepage. Acute decompensated heart failure. Can J Cardiol 2008;24(Suppl B):6B-8B.}

\begin{abstract}
Acute decompensated heart failure is the most common cause of hospitalization for patients older than 65 years of age. Although treatment of this condition has improved over the past two decades, the specific approach to patients in the acute setting has not evolved in the same way. A patient facing acute decompensation is experiencing a serious medical condition that is associated with a poor prognosis. In addition, acute decompensated heart failure results in significant costs to the health care system. Significant morbidity and mortality are associated with patients who are readmitted within a year of the first hospitalization. Because of this important problem, further research on improving the prognosis for this condition is warranted. The present article will focus on the risk factors associated with acute decompensation and the importance of this condition, both on prognosis and economics.
\end{abstract}

Key Words: Acute heart failure; Incidence; Morbidity; Mortality; Pathophysiology

\section{L'insuffisance cardiaque aiguë décompensée}

L'insuffisance cardiaque (IC) aiguë décompensée est la cause la plus fréquente d'hospitalisation chez les patients âgés de plus de 65 ans. Bien que le traitement général de la maladie se soit amélioré au cours des deux dernières décennies, le traitement particulier des patients en état de crise, lui, n’a pas évolué aussi rapidement. Les malades présentant une décompensation aiguë se trouvent dans un état grave, associé à un sombre pronostic. De plus, l'IC aiguë décompensée engendre des coûts élevés pour le système de soins de santé. La réadmission des patients au cours de l'année suivant la première hospitalisation comporte une forte morbidité et une forte mortalité. L'ampleur du problème justifie donc la poursuite de la recherche sur l'amélioration du pronostic de la maladie. Le présent article porte surtout sur les facteurs de risque associés à la décompensation aiguë et sur l'importance de la maladie, tant sur le plan du pronostic que sur celui des coûts.
Leart failure is a complex syndrome that is usually recognized by 1 typical findings of low cardiac output associated with signs of pulmonary and systemic congestion. This clinical syndrome affects between $1 \%$ and $2 \%$ of the adult Canadian population, with an estimated prevalence of more than 450,000 patients across the country (1).

Heart failure patients have three main possible outcomes: remain stable without acute decompensation or fatal events; experience sudden cardiac death; or present with acute decompensation. Canadian incidences of heart failure have been explored by the Canadian Institute for Health Information (CIHI) during the year 2000-2001. In that registry, more than 106,000 patients were hospitalized for heart failure (1).

Heart failure is a progressive syndrome associated with significant morbidity and mortality, and is the most common cause of hospitalization for individuals aged 65 years and older in Canada. Hospitalization for heart failure represents an important event in the life of a cardiac patient. It is associated with a high in-hospital mortality of $15.8 \%$, and $32 \%$ are readmitted within one year (1). Although these data may seem impressive, current trends in this disease process are forecasting an increase in incidence. Projections for the year 2050, based on current data, show that the number of patients hospitalized for heart failure in Canada will triple during this interval (2). Patients with ischemic heart disease are expected to have improved survival through better handling of risk factors and better prevention. Comorbidities associated with high cardiovascular risk, such as diabetes, will be increasing. Patients surviving acute events will be older, which by itself is known to be a very significant predictor for heart failure. These conditions will all contribute to the increased incidence and prevalence of heart failure over time.
BURDEN ON THE HOSPITAL SYSTEM

Apart from the impact on the quality of life of our patients, a hospitalization has a significant economic impact on the health care system. This annual cost has been estimated to be between 1.4 and 2.3 billion dollars in Canada (3). Of interest in this estimate, the cost for treatment of complications is associated with the direct cost of hospitalization. Prevention of such complications will have a significant impact on total cost. Models have been used to justify the use of specific markers, such as B-type natriuretic peptide (4), because improved compliance with guidelines with an increased use of medications (eg, angiotensin-converting enzyme inhibitors, angiotensin receptor blockers, beta-blockers) and the appropriate use of cardiac resynchronization therapy has been proven to reduce hospitalization $(5,6)$. Acute decompensated heart failure or acute worsening of chronic heart failure represent three-quarters of hospitalizations due to heart failure according to the Acute Decompensated Heart Failure National Registry (ADHERE) (7).

A further burden to the system is the frequency of hospital readmissions after an index event. Recurrence of heart failure is very frequent, estimated at $8.7 \%$ at 30 days, $14.1 \%$ at 90 days and up to $23.6 \%$ at one year (8). This readmission rate can be significantly reduced with appropriate follow-up, with the establishment of heart failure clinics proven to be effective in this setting. Finally, the length of stay for these patients varies extensively in the literature, ranging from four to 10 days (9). Comprehensive data are available from the ADHERE registry; $20 \%$ of patients received care in the intensive care unit or cardiac care unit with a median length of stay of 2.5 days. Total hospital stay in this large database averaged 4.3 days (7). Canadian data reference the length of stay for an incident heart failure admission noted as the primary diagnosis at 
10.2 days with a median of 8.0 days (2). Ko et al (9) also found the mean length of stay to be significantly longer in a Canadian cohort compared with the United States cohort (8.5 versus 6.1 days; $\mathrm{P}<0.001$ ), and the 30-day mortality was also higher in the Canadian cohort. These differences in short-term mortality and hospital length of stay, as well as process of care between the United States and Canada, appears to be multifactorial (9).

\section{PATHOPHYSIOLOGY OF ACUTE DECOMPENSATED HEART FAILURE}

In $75 \%$ of cases, acute decompensation occurs in a patient with known chronic heart failure; $25 \%$ have new-onset heart failure (9). Of importance, more than one-third of patients experiencing acute decompensated heart failure will have preserved systolic function, and the outcomes of patients with preserved systolic function seem to be similar to those with decreased systolic function $(10,11)$. Interesting data from a prospective trial of patients with known heart failure are available from the Randomized Evaluation of Strategies for Left Ventricular Dysfunction (RESOLVD) pilot study (10). This trial recruited 768 patients with congestive heart failure and an ejection fraction of less than $40 \%$. They were randomly assigned to receive either an angiotensin-converting enzyme inhibitor or an angiotensin receptor blocker, or a combination of both, for 17 weeks followed by randomization to a beta-blocker or placebo for 26 weeks. During a 43-week period, 180 patients experienced 323 episodes of worsening heart failure, with 143 patients requiring hospitalization. Factors implicated in the deterioration included noncompliance with salt and water restriction (22\%), noncardiac causes (mostly related to pulmonary infections) (20\%), medication adjustments (15\%), use of an antiarrhythmic agent within two days $(15 \%)$ and arrhythmia (13\%). These patients were thought to be clinically stable and under close surveillance by investigators highly trained in managing patients with heart failure. This set of data provides insight into the frequent confounding factors leading to a hospitalization and the difficulty in preventing deterioration even with close follow-up.

Apart from intercurrent problems, progressive heart failure can also lead to deterioration and hospitalization. This usually involves deterioration in the New York Heart Association functional class, decreasing ejection fraction and a reduction in exercise capacity. This process leads to recurrent hospitalizations and death by progressive heart failure or ventricular arrhythmia.

Heart failure is a multisystem syndrome characterized by abnormalities in cardiac and skeletal muscle and renal function, stimulation of the sympathetic nervous system and a complex pattern of neurohormonal changes. The deterioration in heart failure is not only associated with hemodynamic changes such as increased right and left ventricular filling pressures and reduced cardiac output, but are also associated with increases in inflammatory cytokines such as tumour necrosis factoralpha and interleukin (IL)-1beta, IL-6, IL-18; and inflammatory chemokines such as monocyte chemoattractant peptide-1, IL-8 and macrophage inflammatory protein-1 alpha. Thus, therapies should target not only improvement in hemodynamic alterations, but also have beneficial effects on the pathophysiological processes that contribute to the acute hemodynamic decompensation and progression of heart failure $(12,13)$

\section{SUMMARY}

The mechanisms underlying the progression of heart failure can be categorized as:

- sustained neurohormonal stimulation (sympathetic system and the renin-angiotensin-aldosterone system);

- inflammation/oxidative stress;

- hypoxemia and structural abnormalities of cardiomyofibroblasts (apoptosis, necrosis and activation of matrix metalloproteinases);
- abnormalities in arterial and peripheral baroreceptors; and

- pulmonary and ventilatory abnormalities.

Presenting signs and symptoms may be progressive and include increase in body weight, shortness of breath and edema. The diagnosis of acute decompensated heart failure may be difficult at times, and the clinical assessment and patient profiling is essential for appropriate therapy. Clinical assessment of congestion and tissue perfusion at the time of admission is paramount for the most appropriate choice of medical treatment and risk prognosis.

Finally, the profile of patients hospitalized for acute heart failure is changing. Data from ADHERE (7) and EuroHeart Failure survey data (14) reveal strikingly different characteristics in patients in these registries compared with those usually randomized in clinical trials. Associated conditions include evidence of prior ischemic heart disease in $68 \%$, myocardial infarction in $32 \%$, hypertension in up to $72 \%$, cardiac valvular disease in $23 \%$, atrial fibrillation in $31 \%$, peripheral vascular disease in $18 \%$, chronic renal failure in up to $30 \%$ of patients and diabetes in approximately $45 \%$ of cases. These surveys established that patients requiring care are older, with a mean age between 70 and 75 years, are commonly female and have greater concomitant disease, making them more susceptible to decompensation, more difficult to treat and more prone to recurrent events. Other information from these large databases reveals that the clinical presentation of patients with acute heart failure includes (7):

- heart failure with systolic blood pressure (SBP) greater than $140 \mathrm{mmHg}(50 \%)$

- heart failure with SBP $90 \mathrm{mmHg}$ to $140 \mathrm{mmHg}$ (48\%);

- heart failure with SBP less than $90 \mathrm{mmHg}$ (2\%);

- cardiogenic shock (less than 1\%);

- dyspnea $(90 \%)$;

- evidence of pulmonary congestion (74\%); and

- pulmonary edema (less than 3\%).

These characteristics suggest that the clinical presentation is quite variable, making the diagnosis more challenging. Although advances in the understanding of chronic heart failure have established clear guidelines for treatment that have resulted in improved survival, the prognosis for patients hospitalized with acute heart failure syndromes remains poor. Our current approach, especially in the acute care setting, needs further studies in an effort to reduce the duration of hospitalization, improve patient symptoms, decrease the number of the rehospitalizations and improve survival.

DISCLOSURE: No conflicts of interest to report.

\section{REFERENCES}

1. Tsuyuki RT, Shibata MC, Nilsson C, Hervas-Malo M Contemporary burden of illness of congestive heart failure in Canada. Can J Cardiol 2003;19:436-8.

2. Johansen H, Strauss B, Arnold JMO, Moe G, Liu P. On the rise: The current and projected future burden of congestive heart failure hospitalization in Canada. Can J Cardiol 2003:4:430-5.

3. Bentkover JD, Stewart EJ, Igmaszewski A, Lepage S, Liu P, Cooper J. New technologies and potential cost savings related to morbidity and mortality reduction in class III/IV heart failure patients in Canada. Int J Cardiol 2003;88:33-41.

4. Moe GW, Howlett J, Januzzi JL, Zowall H; Canadian Multicenter Improved Management of Patients With Congestive Heart Failure (IMPROVE-CHF) Study Investigators. N-terminal pro-B-type natriuretic peptide testing improves the management of patients with suspected acute heart failure: Primary results of the Canadian prospective randomized multicenter IMPROVE-CHF study. Circulation 2007;115:3103-10. 
5. Shibata MC, Nilsson C, Hervas-Malo M, Jacobs P, Tsuyuki RT. Economic implications of treatment guidelines for congestive heart failure. Can J Cardiol 2005;21:1301-6.

6. Arnold JM, Howlett JG, Dorian P, et al. Canadian Cardiovascular Society Consensus Conference recommendations on heart failure update 2007: Prevention, management during intercurrent illness or acute decompensation, and use of biomarkers. Can J Cardiol 2007;23:21-45

7. Lee DS, Johansen H, Gong Y, Hall RE, Tu JV, Cox JL; Canadian Cardiovascular Outcomes Research Team. Regional outcomes of heart failure in Canada. Can J Cardiol 2004;20:599-607.

8. Ko DT, Tu JV, Masoudi FA, et al. Quality of care and outcomes of older patients with heart failure hospitalized in the United States and Canada. Arch Intern Med 2005;165:2486-92.

9. Fonarow GC; ADHERE Scientific Advisory Committee. The Acute Decompensated Heart Failure National Registry (ADHERE): Opportunities to improve care of patients hospitalized with acute decompensated heart failure. Rev Cardiovasc Med 2003;7:21-30.
10. Tsuyuki RT, McKelvie RS, Arnold JM, et al. Acute precipitants of congestive heart failure exacerbations. Arch Intern Med 2001;161:2337-42.

11. Bhatia RS, Tu JV, Lee DS et al. Outcome of heart failure with preserved ejection fraction in a population-based study. $\mathrm{N}$ Engl J Med 2006;355:260-9.

12. Colucci WS, Braunwald E. Pathophysiology of heart failure. In Zipes DP, ed. Braunwald's Heart Disease: A Textbook of Cardiovascular Medicine, 7th edn. Philadelphia: Elsevier Saunders, 2005:509-38

13. Colucci WS. Pathophysiology of heart failure: Neurohumoral adaptations. UpToDate 2008:15.3.

14. Cleland JG, Swedberg K, Follath F, et al; Study Group on Diagnosis of the Working Group on Heart Failure of the European Society of Cardiology. The EuroHeart Failure survey programme - a survey on the quality of care among patients with heart failure in Europe. Part 1: Patient characteristics and diagnosis. Eur Heart J 2003;24:442-63. 